\title{
CONTROLE GERENCIAL: UMAANÁLISE NAS EMPRESAS CONTÁBEIS DA CIDADE DE CAICÓ/RN.
}

\author{
Hugo Azevedo Rangel de Morais ${ }^{1}$, Stepherson Rodrigo Alves de Oliveira ${ }^{2}$
}

\begin{abstract}
RESUMO
O controle gerencial de uma empresa é necessário para um eficiente desenvolvimento interno. Com as mudanças constantes das legislações e a evolução da tecnologia da informação nas empresas contábeis, é essencial o controle gerencial eficiente, através dele será possível identificar como está a vida da empresa no seu dia a dia. Neste trabalho é mostrada a importância do controle gerencial para as empresas contábeis, situada na cidade de Caicó/RN, demonstrando a sua importância para auxiliar nas tomadas de decisões. O presente estudo tem como objetivo geral de analisar se nas empresas contábeis da cidade de Caicó possuem controle gerencial que os auxiliem nas tomadas de decisões, verificando se existem a prestação de serviço de contabilidade gerencial e analisando sua importância para os empresários. Quanto a metodologia é classificada como descritiva, do ponto de vista de sua natureza é uma pesquisa aplicada, tendo uma abordagem qualitativa e de caráter exploratório, já no que se refere aos procedimentos técnicos trata-se de um levantamento. Observou que os empresários julgam ter conhecimento em relação à importância do controle gerencial, apresentando 57,14\% alegam existir controle gerencial, metade dos entrevistados dedicam controle em todos os departamentos, destacando-se posteriormente o setor financeiro com $21,44 \%$, por fim, $92,86 \%$ relataram necessitar de aperfeiçoamento acerca dos controles consequentemente gestão empresarial.
\end{abstract}

Palavras-chave: Controle gerencial. Empresas contábeis. Tomada de decisões.

\section{INTRODUÇÃO}

O controle gerencial de uma empresa está ligado com à contabilidade gerencial e à controladoria que é necessário para um eficiente desenvolvimento interno, portanto observa que a fiscalização dos trabalhos passa a ser também eficiente, dependendo da qualidade da análise realizada pelos gestores, pois não existe controle mediante um simples fornecimento de informação, segundo Figueiredo e Caggiano (2004, p. 46) "controle é um sistema de feedback que possibilita aos desempenhos serem comparados com os objetivos planejados; controle é essencial para a realização do planejamento", demonstrando que só pode ter um controle se houver um planejamento, para obter o conhecimento do que se vai controlar.

Neste trabalho será mostrada a importância do controle gerencial para as empresas contábeis, situada na cidade de Caicó/RN, demonstrando a sua importância para auxiliar nas tomadas de decisões. Com fortalecimento do mercado, as mudanças de legislação e a evolução da tecnologia de informação nas empresas contábeis, torna-se necessário o controle gerencial eficiente, pois através dele será possível saber como está à vida da empresa no seu

\footnotetext{
${ }^{1}$ Universidade do Estado do Rio Grande do Norte - UERN.

${ }^{2}$ Faculdade Católica Santa Teresinha - FCST - Caicó/RN. 
dia a dia, para poder prestar um serviço com maior qualidade para os clientes, levando informações relevantes e obtendo excelência na prestação de serviço.

Diante do exposto, temos como problema da pesquisa: Como os contadores veem o controle gerencial em seus respectivos escritórios na cidade de Caicó/RN?

O presente estudo tem como objetivo geral mostrar a visão dos contadores sobre o controle gerencial na cidade de Caicó/RN; e como objetivos específicos: 1) verificar se as empresas prestam o serviço de contabilidade gerencial para seus clientes; 2) saber se existe planejamento nas empresas contábeis para ter um controle gerencial; 3) verificar na visão dos entrevistados a qualidade do controle gerencial nas suas empresas; 4) analisar as percepções da importância do controle gerencial para os empresários.

Esse trabalho torna-se relevante, mostrando a relevância do controle gerencial para as empresas contábeis, através de uma pesquisa com os empresários contábeis. A contextualização do tema será através de pesquisa bibliográfica em livros, revistas, artigos, para ter um bom conhecimento da temática. A metodologia desenvolvida na pesquisa referente aos objetivos é classificada como descritiva, do ponto de vista de sua natureza é caracterizada como pesquisa aplicada, tendo uma abordagem qualitativa e de caráter exploratório, já no que se refere aos procedimentos técnicos trata-se de um levantamento, voltando-se a um estudo em relação ao gerenciamento e procedimentos do controle gerencial cujo comportamento se deseja conhecer.

\section{DISCUSSÃO TEÓRICA}

A contabilidade é uma ciência fundamental na vida econômica aonde vem desde os primórdios, tendo como ramo a contabilidade gerencial, controladoria, entre outros, que trás a discussão da gerência das instituições ou empresas mediante ao controle, portanto esse controle deve ser estratégico, pois atinge todos os setores ou departamentos de uma instituição, porém para existir um controle deve existir o planejamento para delimitar o que o controle vai controlar e auxiliando aos gestores nas tomadas de decisões.

\subsection{CONTABILIDADE GERENCIAL}

A contabilidade gerencial advém da própria contabilidade financeira, no entanto, sem os padrões normativos e regulatórios que tangenciam a contabilidade tradicional. Nessa perspectiva a contabilidade gerencial privilegia a informação e se utiliza de várias ferramentas como relatórios, orçamentos, precificações, análise de custos, entre outros. A partir dessa 
premissa tem-se artefatos para uma boa gestão e melhores práticas para administração dos negócios.

A contabilidade gerencial, num sentido mais profundo, está voltada única e exclusivamente para a administração da empresa, procurando suprir informações que se "encaixem" de maneira válida e efetiva no modelo decisório do administrador. (IUDÍCIBUS, 2006, p. 21).

Para alcançar um gerenciamento adequado e com agilidade, é necessário ter um bom sistema de informação, que é um complexo de elementos em interação se comunicando com os setores ou departamentos, podendo ser um sistema de apoio à decisão ou um sistema de gestão empresarial, ambas são informações aglutinadas de subsistemas que apresentam informações históricas e atuais, e um provável futuro.

A Contabilidade Gerencial está totalmente ligada ao controle gerencial, pois se traduz como sendo o fiscal dos controles da gerência dentro das empresas, assim como disse o escritor, a contabilidade gerencial não é uma técnica especifica e sim um controle de sistemas da empresa para melhorar o seu desempenho, pode ter vasto conhecimento sobre procedimentos, técnicas e não colocar em ação então não terá um controle, o controle tem que existir, tem que estar em prática, o controle tem que ser ativo para resguardar os próprios ativos da empresa, tem que ser real e não fictício.

\subsubsection{Controle Interno}

O controle interno é o acompanhamento do planejamento e normas da empresa, faz parte da contabilidade gerencial e da controladoria, muitas vezes se misturam uma vez que tem as mesmas finalidades, que é auxiliar a empresa na tomada de decisão. Como o nome já diz o controle interno começa de dentro para fora, tendo uma visão de fiscalização. Vários autores colocam diversos conceitos, mas segundo Crepaldi (2004, p. 73) o conceito de controle interno é:

Podemos definir controle interno como o sistema, de uma empresa, que compreende o plano de organização, os deveres e responsabilidade todos os métodos e medidas adotadas com a finalidade de :

- salvaguarda os ativos;

- verificar a exatidão e fidelidade dos dados e relatórios contábeis e de outros dados operacionais;

- desenvolver a eficiência nas operações;

- comunicar e estimular o cumprimento das políticas, normas e procedimentos administrativos. 
Esse conceito mostra que o controle interno objetiva proteger a empresa tanto nos seus ativos quanto na parte operacional e nas políticas administrativas, contribuindo para uma contabilidade eficiente. O controle interno é de grande importância para o desenvolvimento da empresa, pois proporciona menores desperdícios de tempo e financeiro, uma vez que, em uma empresa contábil tempo é dinheiro, pois se trabalha com prazos e o não cumprimento gera multas e punições ao contribuinte

\subsection{CONTROLADORIA}

A controladoria vem para auxiliar os gestores das empresas através de sistemas de informação, tanto da contabilidade financeira quanto da contabilidade gerencial, sendo uma área da empresa que visa controlar os objetivos determinados pelas organizações, independente do porte, pois toda organização tem seus objetivos, devendo haver um setor para controlar, em uma empresa de pequeno porte pode não possuir o setor, mas tem um controle feito pela gerência da empresa.

Segundo Figueiredo e Caggiano (2004, p. 26):

A missão da Controladoria é zelar pela continuidade da empresa, assegurando a otimização do resultado global. [...] O órgão administrativo Controladoria tem por finalidade garantir informações adequadas ao processo decisório, colaborando com os gestores na busca da eficácia gerencial.

Mosimann e Fisch (1999 apud POLITELO et al. 2014) entendem que a missão da controladoria consiste em otimizar os resultados econômicos da empresa objetivando garantir sua continuidade através da integração de esforços das suas diversas áreas.

O controle é essencial para zelar pela empresa buscando continuidade e resultados positivos, como diz a citação acima, a controladoria é um órgão da empresa que visa garantir informação que fortaleça no processo decisório dos gestores. Já segundo Nascimento e Reginato (2009, p. 2) a área da controladoria tem como função de:

Promover a eficácia das decisões monitorando a execução dos objetivos estabelecidos, investigando e diagnosticando as razões para a ocorrência de eventuais desvios entre os resultados alcançados e os esperados, indicando as correções de rumo, quando necessárias, e, principalmente, suavizando para os gestores as imponderabilidades das variáveis econômicas, através do provimento de informações sobre operações passadas e presentes e de sua adequada comunicação, de forma a sustentar a integridade do processo decisório. 
Portanto, a função da controladoria é auxiliar na tomada de decisões mediante informações relevantes sobre os objetivos, com desvios ou não, buscando as correções de rumo, para voltar aos objetivos traçados no planejamento. Para essa função da área de controladoria é necessário um profissional que tenha conhecimento em várias áreas, principalmente em administração e em contabilidade, esse profissional é conhecido como controller ou controlador, ele pode ser o chefe da contabilidade desde que suas funções não tenham que se restringir apenas às funções contábeis e sim em toda aplicação gerencial da empresa.

$\mathrm{Na}$ controladoria existe o modelo de gestão onde se define a forma de administrar o negócio com relação aos elementos e variáveis empresariais, como planejamento, controle, informação, entre outros. Segundo Frezatti et al (2009, p. 48):

\footnotetext{
O modelo de gestão é a maneira própria, única, individual de cada empresa administrar os seus negócios, ainda que, mesmo quando não estiver formalizada, se torna visível a partir do desenvolvimento das ações praticadas pelos controladores e pelos gestores. Por trás dessas ações, crenças, valores e sentimentos dos controladores e gestores estão presentes, direcionando a entidade.
}

As definições que ocorrem de crenças, valores e sentimentos na empresa, podem modificar ideias que impactam todos os departamentos e subsistemas empresariais deixando sem direcionamento.

$\mathrm{Na}$ controladoria existem funções que são de grande importância para alcançar um ciclo de retorno de informações aos gestores: Planejamento, Execução, Controle, Feedback, para auxiliar a tomada de decisão das organizações.

Para as empresas essas funções são de fundamental importância, pois deve existir um planejamento do que será executado, e no decorrer da execução um controle para fiscalizar se está sendo realizado o que foi planejado, o resultado do controle são as informações tratadas como feedback, repassadas para os administradores e gestores que são os responsáveis pelo planejamento, esse ciclo vem para auxiliar os empresários a tomarem decisões.

Acerca das funções da controladoria, Borinelli (2006) destaca, a partir de algumas obras, as diferentes funções e atividades desenvolvidas pela controladoria. No quadro a seguir detalhouse as funções e atividades respectivas. 
Quadro 1 -Funções e atividades da controladoria.

\begin{tabular}{|c|c|}
\hline Função & Atividades \\
\hline Contábil & $\begin{array}{l}\text { Gerenciar as atividades de contabilidade, } \\
\text { implementar e manter todos os registros contábeis } \\
\text { (processamento contábil), elaborar as demonstrações } \\
\text { contábeis, atender aos agentes de mercado } \\
\text { (stakeholders) em suas demandas informacionais, } \\
\text { proceder à análise interpretativa das demonstrações } \\
\text { contábeis e desenvolver políticas e procedimentos } \\
\text { contábeis e de controle. }\end{array}$ \\
\hline Gerencial-Estratégica & $\begin{array}{l}\text { Coordenar, assessorar e consolidar os processos de } \\
\text { elaboração dos planos empresariais, orçamento e } \\
\text { previsões; criar condições para a realização do } \\
\text { controle, através do acompanhamento dos planos e } \\
\text { das decisões tomadas; auxiliar na definição de } \\
\text { métodos e processos para medição do desempenho } \\
\text { das áreas organizacionais, assim como dos gestores; } \\
\text { auxiliar na definição e gestão de preços de } \\
\text { transferência gerenciais; realizar estudos sobre } \\
\text { análise de viabilidade econômica de projetos de } \\
\text { investimento; realizar estudos especiais de natureza } \\
\text { contábil-econômica; desenvolver condições para a } \\
\text { realização da gestão econômica e proceder à } \\
\text { avaliação econômica. }\end{array}$ \\
\hline Custos & $\begin{array}{l}\text { Registrar, mensurar, controlar, analisar e avaliar os } \\
\text { custos da organização, incluindo análises gerenciais } \\
\text { e estratégicas referentes à viabilidade de } \\
\text { lançamentos de produtos e serviços, resultados de } \\
\text { produtos e serviços, de linhas de negócios e de } \\
\text { clientes. }\end{array}$ \\
\hline Tributária & $\begin{array}{l}\text { Registrar, apurar e controlar impostos, tributos e } \\
\text { contribuições, bem como elaborar o Planejamento } \\
\text { Tributário da organização. }\end{array}$ \\
\hline Proteção e Controle dos Ativos & $\begin{array}{l}\text { Estabelecimento e monitoramento do sistema de } \\
\text { controles internos, destinado a proteger o patrimônio } \\
\text { organizacional e salvaguardar os interesses da } \\
\text { entidade. }\end{array}$ \\
\hline Controle de Riscos & $\begin{array}{l}\text { Identificar, mensurar, analisar, avaliar, divulgar e } \\
\text { controlar os diversos riscos envolvidos no negócio, } \\
\text { bem como seus possíveis efeitos. }\end{array}$ \\
\hline Gestão da Informação & $\begin{array}{l}\text { Desenvolver, implementar e gerir os sistemas de } \\
\text { informações, no que tange às informações contábeis, } \\
\text { econômicas, financeiras e patrimoniais, estando fora } \\
\text { do escopo de suas funções a preocupação com o } \\
\text { gerenciamento da tecnologia e infraestrutura dos } \\
\text { sistemas. }\end{array}$ \\
\hline
\end{tabular}

Fonte: Borinelli (2006)

Como detalhado acima no Quadro 1, muitas são as funções da controladoria, de modo que a mesma apresenta-se como um órgão, que compõe a organização, que se inter-relaciona com diferentes áreas, fornecendo apoio à gestão em diversos níveis da companhia. 


\subsubsection{Planejamento}

O planejamento é de grande importância para as organizações, onde serão traçadas as metas, os objetivos, as estratégias, nortear o futuro da empresa, para Figueiredo e Caggiano (2004, p. 43) "Planejamento é a mais básica de todas as funções gerencias, e a habilidade com que esta função está sendo desempenhada e determina o sucesso de todas as operações", se o planejamento for mal elaborado as outras funções não obterão sucesso nos seus objetivos, pois o planejamento é à base de um ciclo empresarial consistente, retornando com informações. Segundo Frezatti (2000, p. 22):

Planejar é quase uma necessidade intrínseca, como o alimentar-se para o ser humano. Não se alimentar significa enfraquecimento e o mesmo ocorre com a organização, caso o planejamento não afete o seu dia-a-dia dentro do seu horizonte mais de longo prazo.

O planejamento é necessário para as empresas alcançarem o aperfeiçoamento da organização, pois com um bom planejamento, irá alcançar a diretriz para manter uma organização sustentável podendo chegar a informação constantemente para auxiliar nas tomadas de decisões.

\subsubsection{Execução}

As execuções podem também ser chamadas de operações ou procedimentos, é a fase onde são colocados em prática os objetivos definidos no planejamento da empresa. Para Chiavenato (2007, p. 178) os procedimentos "Formam a sequência de passos ou de etapas que devem ser rigorosamente seguidos para a execução de planos", para cada ação deve haver um procedimento da execução, tendo uma lógica de sequências prefixadas do modo como executar a tarefa, segundo Chiavenato (2003, p. 60) "Tarefa é toda atividade executada por uma pessoa no seu trabalho dentro da organização", acompanhando desde procedimentos até a fase final, que juntos executam o que foi planejado sendo controlados constantemente dentro da organização.

\subsubsection{Controle}

O controle é um mecanismo no qual são medidos e fiscalizados os resultados das tarefas executadas, previamente determinados no planejamento, segundo Chiavenato (2007, p. 334) o conceito de controle é: 
A essência do controle consiste em verificar se a atividade controlada está ou não alcançando os resultados desejados. Quando se fala em resultados desejados, partese do princípio de que esses resultados foram previstos e precisam ser controlados. Então, o controle pressupõe a existência de objetivos e planos, pois não se pode controlar sem planos para definir o que deve ser feito. O controle verifica se a execução está de acordo com o que foi planejado.

Controlar é verificar algo que já foi determinado anteriormente, pois com um controle eficiente terá segurança no resultado do objetivo que foi planejado, para controlar é necessário saber os planos previstos, podendo comparar se está de acordo ou não com o planejamento, fazer correções no decorrer da execução permitindo-lhe alcançar os resultados desejados, não é possível controlar o que não conhece ou o que não foi determinado,.

\subsubsection{Feedback (Informações)}

O feedback é o retorno das informações para os gestores que elaboram o planejamento, essas informações são de grande importância para tomada de decisão, pois são elas que norteiam os gestores da forma como estão sendo executados os procedimentos para alcançar os objetivos planejados, essa informação somente será alcançada com um controle bem sucedido. Segundo Figueiredo e Caggiano (2004, p. 46):

Um feedback de informações possibilita ao gestor determinar o progresso que foi feito em busca de realização dos objetivos. [...] A função de controle está ligada intimamente a função de planejamento por um sistema de feedback que informa o resultado de decisões passadas. Este sistema é necessário para avaliação da qualidade do processo decisório e para seu aperfeiçoamento.

O sistema de feedback é a realimentação das informações aos gestores com isso as decisões colocadas no planejamento passado podem ser alteradas, aperfeiçoando para o futuro, pois o ciclo muda de acordo com as influências externas ou internas, e como o controle está ligado intimamente às informações repassadas para os gestores, eles terão que reavaliar o planejamento ou somente aperfeiçoar se tiver tudo conforme foi planejado.

Ferreira et al. (2015) explica que "a teoria da informação estruturou-se pela necessidade de quantificar e qualificar as informações geradas para tomada de decisão. Os recursos tecnológicos empregam suporte para que todos os níveis de uma organização identifiquem suas demandas, solucionem os problemas e produzam resultados adequados." 


\subsection{CONTROLE GERENCIAL OU DE GESTÃO}

O controle gerencial ou de gestão significam gerenciar, onde ligando com o nome controle torna-se uma gerência controlada, abrange toda empresa desde o conhecimento do planejamento à vida psicológica dos colaboradores, para assegurar a vida contínua da empresa, segundo Anthony e Govindarajan (2008) O controle gerencial é o conjunto de atividades desenvolvidas para assegurar que os planos gerenciais sejam atingidos, para isso, necessita de recursos e estruturas a serem desenvolvidos. Esse conhecimento para controlar com eficiência depende de um bom sistema gerencial, pois não é possível controlar tudo ao mesmo tempo sem algumas ferramentas de controle. Anthony e Govindarajan (2002, p.34) definem controle gerencial como "o processo pelo qual os executivos influenciam os outros membros da organização para que obedeçam as estratégias adotadas", os gestores ou os executivos precisam liderar os outros membros que compõem o quadro da empresa, pois todos devem saber dos objetivos a serem alcançados.

Silva(2015) destaca que "tomar decisão dentro de qualquer empresa requer responsabilidade e conhecimento no qual é necessário uma base de dados atualizada, planejamento e ferramentas que possibilitem o controle, processamento e análise dos resultados a serem alcançados e praticados".

Segundo Figueiredo e Caggiano (2004, p. 234) “O controle gerencial é uma atividade subordinada que diz respeito ao uso eficiente dos recursos comprometidos com a realização dos objetivos organizacionais". Os objetivos das empresas necessitam ser alcançados, desde que seja feito o uso correto dos recursos, pois muitas vezes o mau uso dos recursos não auxilia a gerência na tomada de decisão, consequentemente podendo perder receita, já que os recursos não estão sendo usados com eficiência.

\section{PROCEDIMENTOS METODOLOGICOS}

\subsection{CLASSIFICAÇÃO DA PESQUISA}

De acordo com Vergara (2013) podemos dividir os tipos de pesquisas em dois critérios: quanto aos fins e quanto aos meios. Com relação aos fins, as pesquisas se subdividem em exploratória, descritiva, explicativa, metodológica, aplicada ou intervencionista. 
Segundo Gil (2010, p. 42) "as pesquisas descritivas têm como objetivo primordial a descrição das características de determinada população ou fenômeno ou, então, o estabelecimento de relações entre variáveis"

Com o tema abordado e sua contextualização a metodologia do estudo trata-se de pesquisa bibliográfica, fonte secundária sobre o tema, para ter um bom conhecimento no assunto, do ponto de vista de sua natureza é caracterizada como pesquisa aplicada, pois ela irá gerar conhecimento para ser colocada em prática e é de interesse local, tendo uma abordagem qualitativa, pois segundo Filho e Filho (2013, p. 64) "parte de uma visão em que há uma relação dinâmica entre o mundo real e o pesquisador, entre o mundo objetivo e a subjetividade de quem observa que não pode ser traduzida em números".

Enquanto seu objetivo é classificado como descritiva (GIL, 2010), pois será feito um levantamento através de coleta de dados para avaliar a existência de procedimento em relação ao controle gerencial.

\subsection{COLETA E TRATAMENTO DE DADOS}

A pesquisa foi efetuada na cidade de Caicó-RN no mês de novembro do ano de 2014, foi aplicado um questionário identificando a visão dos empresários das empresas contábeis entrevistadas, sendo essas entrevistas feitas nas empresas relacionadas no site da FENACON que se encontra no endereço eletrônico: www.fenacon.org.br/consulta-por-uf.cshtml?uf=RN, não sendo $100 \%$ dos escritórios de contabilidade do município, pois esse número só poderia ser passado pelo CRC-RN e não foi obtido êxito na solicitação, porém foi realizada a pesquisa com as empresas contábeis optantes pelo regime de tributação do Simples Nacional. A pesquisa se deu através de um questionário composto por questões objetivas, sendo aplicada a uma amostra de $70 \%$ das empresas citadas pela FENACON, onde equivale a 14 empresas, de um universo das 20 citadas no total.

\section{PESQUISA E RESULTADOS}

Análise dos dados tem uma base teórica quem vem esclarecer os objetivos citados no trabalho, sendo eles, geral e específicos, identificando a importância do controle gerencial e sua aplicabilidade diante dos serviços desenvolvidos nas empresas contábeis, tanto interno quanto externo, auxiliando aos gestores. 
Gráfico 1 - Em sua empresa existe controle gerencial?

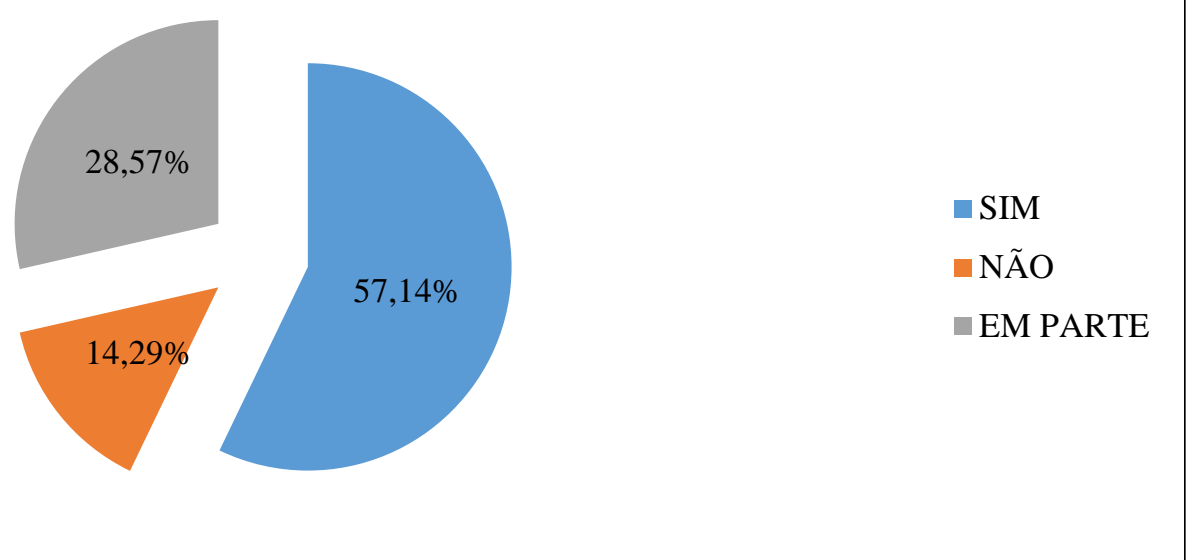

Fonte: Os autores, 2015.

O gráfico acima serve para definir quais empresas tem um controle gerencial, sendo $14,29 \%$ das empresas não tem o controle, $28,57 \%$ tem o controle em parte onde muitas vezes controla apenas alguns setores e na maioria das empresas sendo 57,14\% tem o controle gerencial. Podemos constatar que os contadores, empresários, entendem que realizam esse controle gerencial, nesse sentido pode-se dizer que os mesmos julgam relevante tal iniciativa.

\section{Gráfico 2 - Se existe controle gerencial como você classifica?}

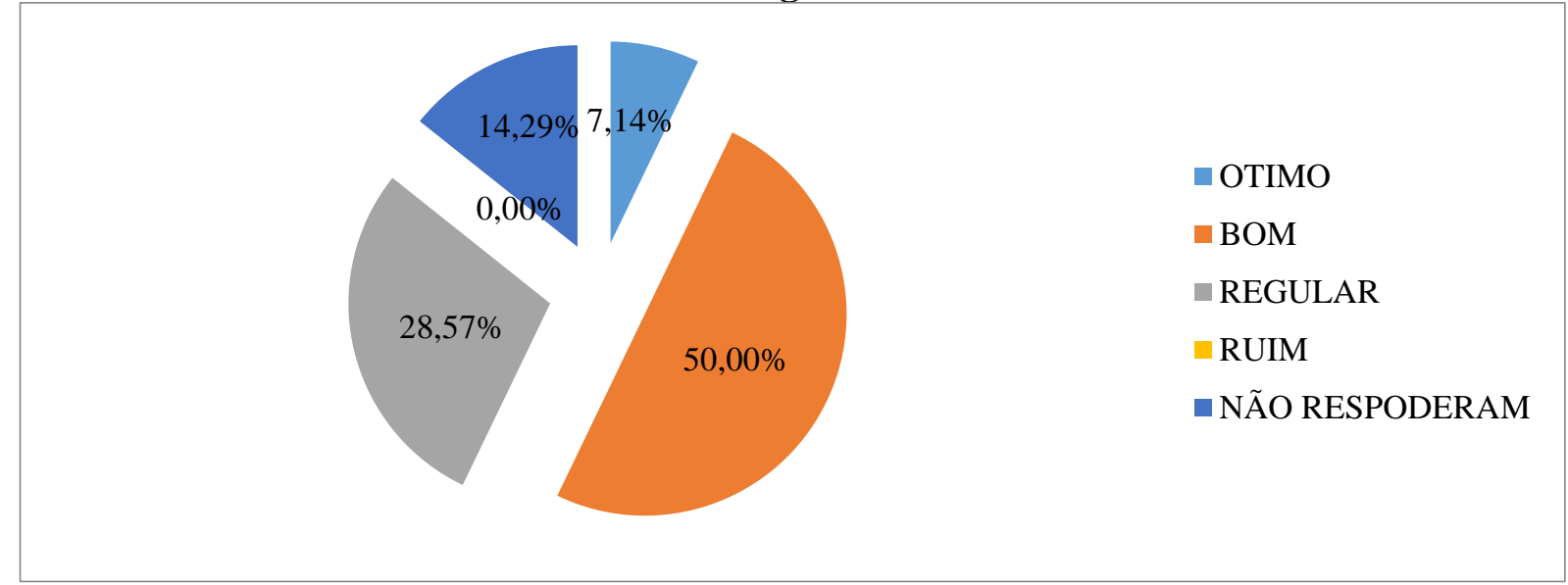

Fonte: Os autores, 2015.

Os resultados do gráfico acima demonstram a classificação do controle das empresas que confirmaram ter o controle ou parte dele, 14,29\% das empresas não responderam esse questionamento por não terem o controle gerencial, enquanto que apenas 7,14\% das empresas consideram seu controle gerencial ótimo, $28,57 \%$ das empresas regular e $50 \%$ dos pesquisados consideram bom. Com isso, conclui-se que $57,14 \%$ entre os $100 \%$ entrevistados 
consideram que seu controle gerencial funciona com qualidade podendo auxiliar nas tomadas de decisões. Nesse sentido, fica evidenciado que o conceito ótimo foi respondido incipiente, o que denota que se faz necessário melhorias.

\section{Gráfico 3 - Para você qual o setor necessita de maior controle?}

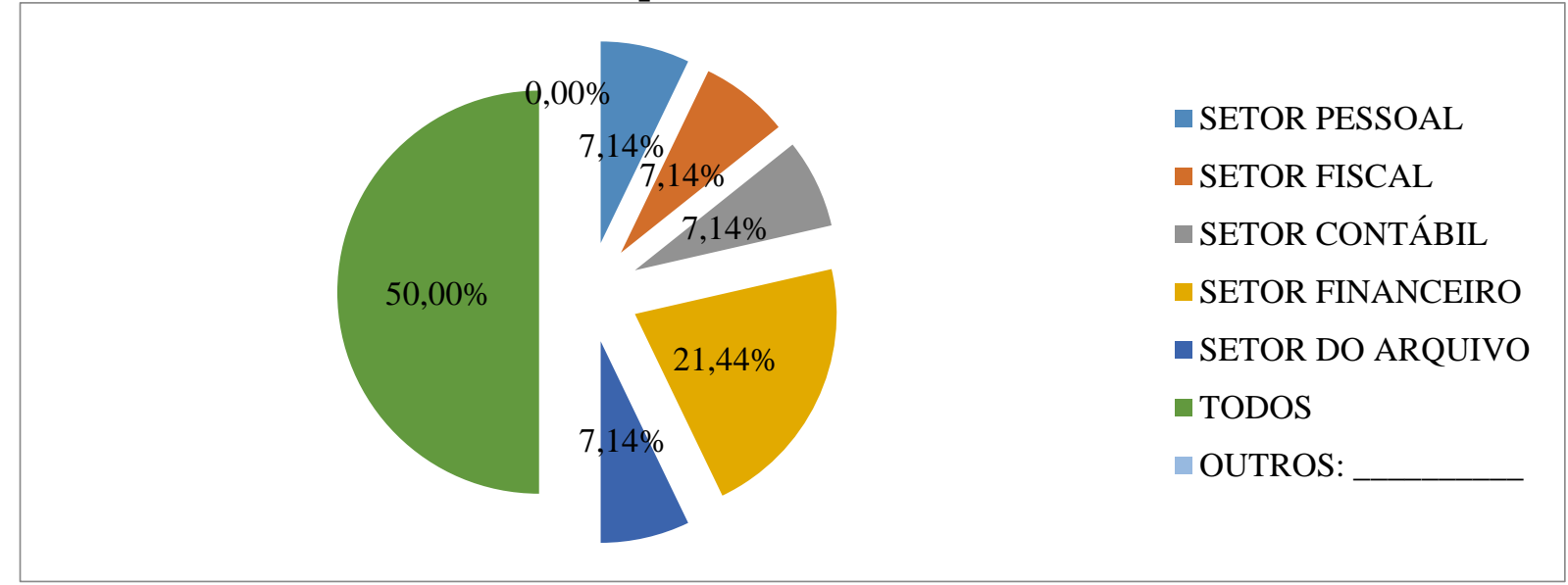

Fonte: Os autores, 2015.

O gráfico acima trás o resultado de qual o setor necessita de maior controle para as empresas contábeis, sendo $7,14 \%$ das empresas considera o setor pessoal, $7,14 \%$ o setor fiscal, $7,14 \%$ o setor contábil, $7,14 \%$ o setor do arquivo, $21,44 \%$ das empresas destacaram o setor financeiro e 50\% empresas consideram que todos os setores são de grande importância para ter um controle gerencial de qualidade, percebendo-se que a maioria das empresas tem uma preocupação em controlar todos os setores, destacando-se também o setor financeiro que individualmente foi o mais citado, o que nos traz uma reflexão para o quesito da cobrança, contas a receber, onde muitos empresários reconhecem como grande gargalo a ser superado dentro das organizações. 
Gráfico 4 -Sua empresa presta o serviço de contabilidade gerencial para os clientes?

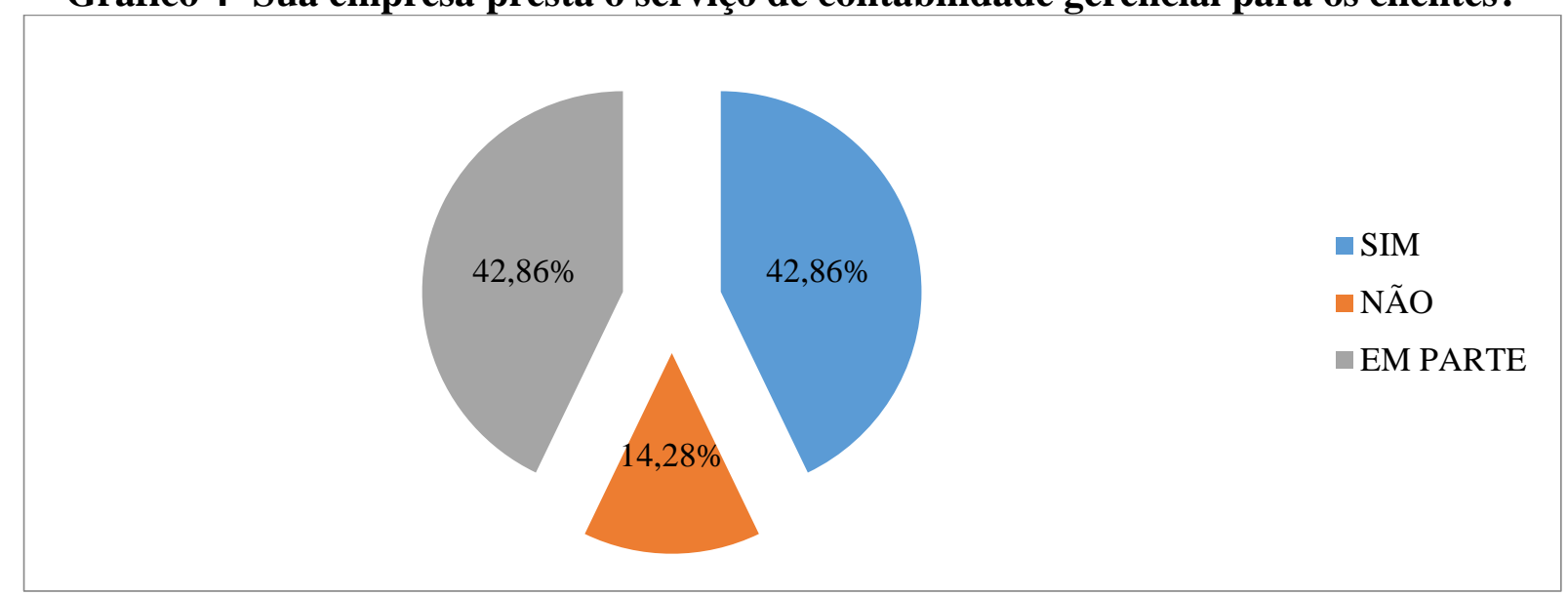

Fonte: Os autores, 2015.

O resultado do gráfico acima se buscou saber se as empresas contábeis prestavam o serviço de contabilidade gerencial para seus clientes, com isso $42,86 \%$ das empresas prestam o serviço de contabilidade gerencial, $42,86 \%$ só prestam o serviço parcialmente, não sendo um serviço completo de informações que auxilie a empresa do cliente e 14,28\% das empresas não prestam o serviço. Vale destacar que os escritórios que não oferecem tem o mesmo percentual aproximado das organizações contábeis que não existe controle conforme o gráfico 2.

\section{Gráfico 5 - Em sua empresa existe planejamento (estratégico)?}

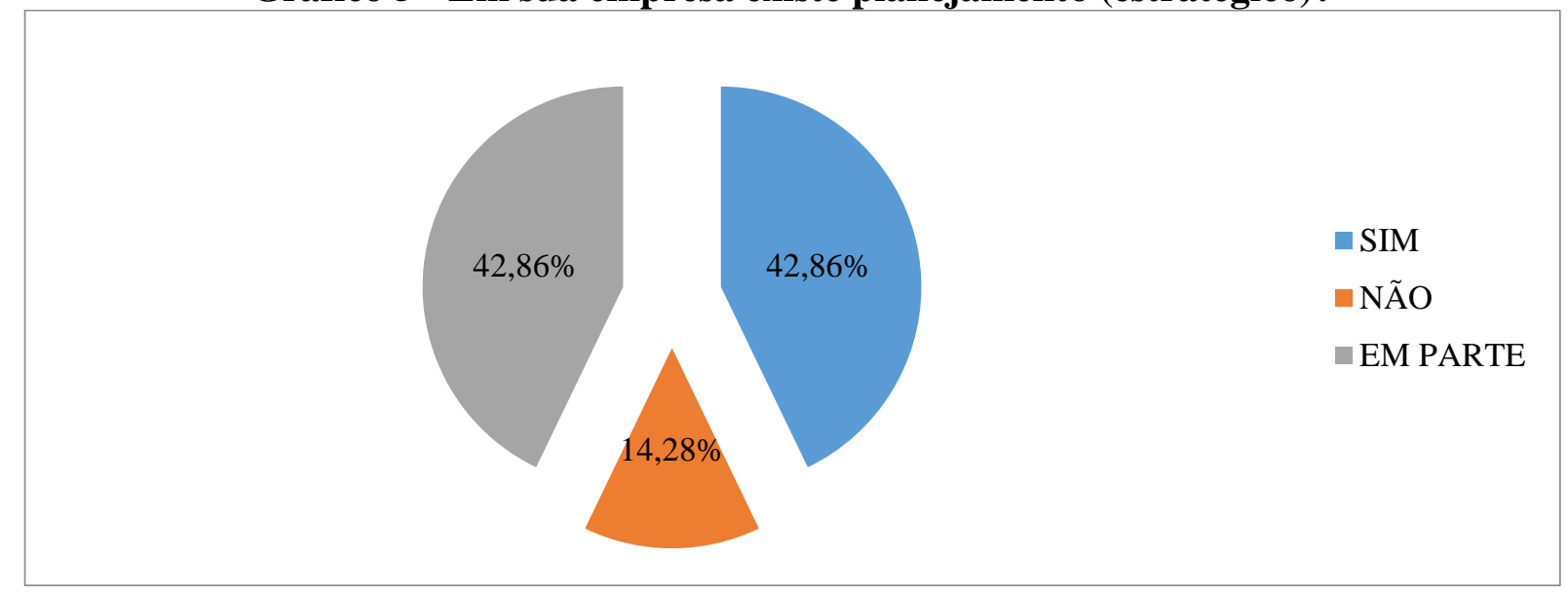

Fonte: Os autores, 2015.

O gráfico acima demonstra o resultado do questionamento que busca saber se as empresas têm planejamento e as respostas demonstram a conformidade dos resultados anteriores onde $42,86 \%$ empresas responderam que sim, tem planejamento outras $42,86 \%$ 
falaram que parcialmente, onde planeja alguns procedimentos e não todos os procedimentos, já 14,28\% das empresas citaram que não existe planejamento, mostrando que quem não tem planejamento não tem controle, pois só pode existir controle mediante um planejamento para decidir o que vai ser controlado.

\section{Gráfico 6 - Como gestor de uma empresa contábil você considera suas ferramentas de controle eficientes?}

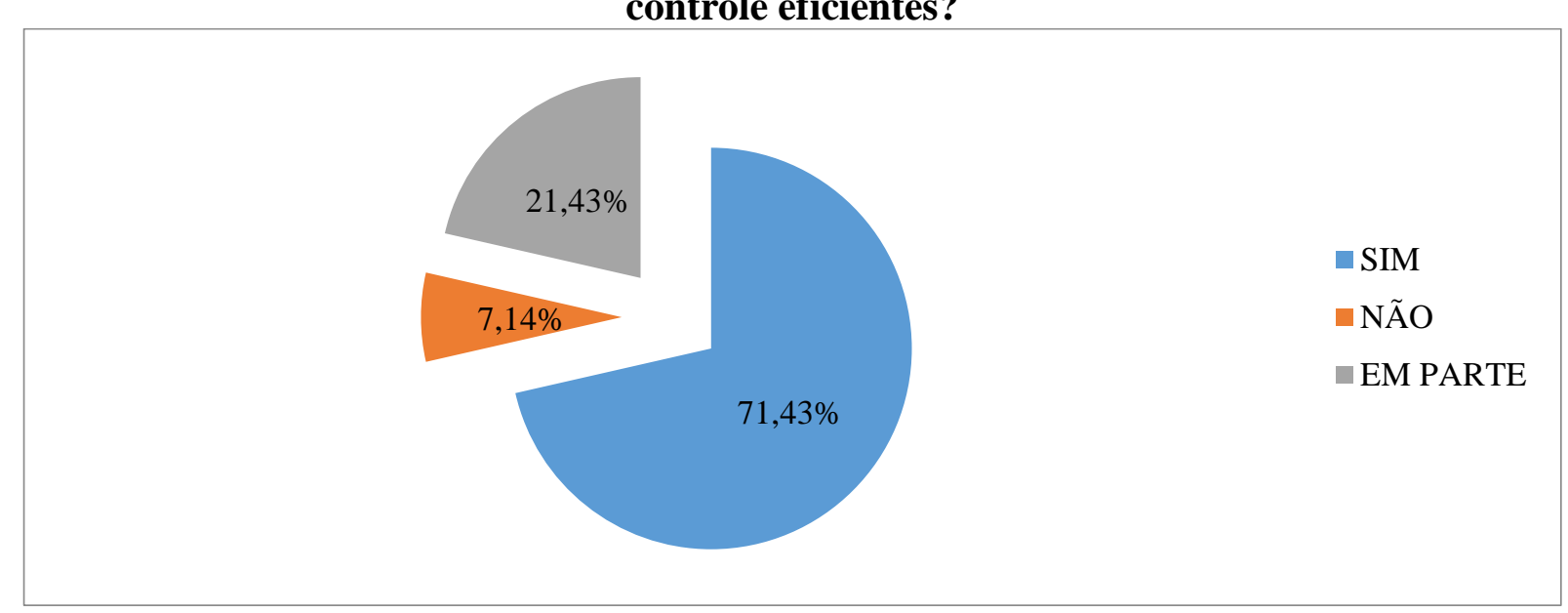

Fonte: Os autores, 2015.

O resultado acima demonstra que a ferramenta de controle gerencial é eficiente para $71,43 \%$ das empresas, $21,43 \%$ considera em parte, e 7,14\% diz que não é eficiente, percebendo-se que $7,14 \%$ das empresas devem procurar ferramentas para obter controles eficientes e 21,43\% necessitam melhorar essas ferramentas. A referida resposta chama atenção porque menos de $8 \%$ não acredita ser eficiente suas ferramentas de controle, no entanto, em respostas anteriores um percentual maior relata não ter o próprio controle na sua própria empresa, ficando evidenciado a má interpretação de alguns respondentes. 


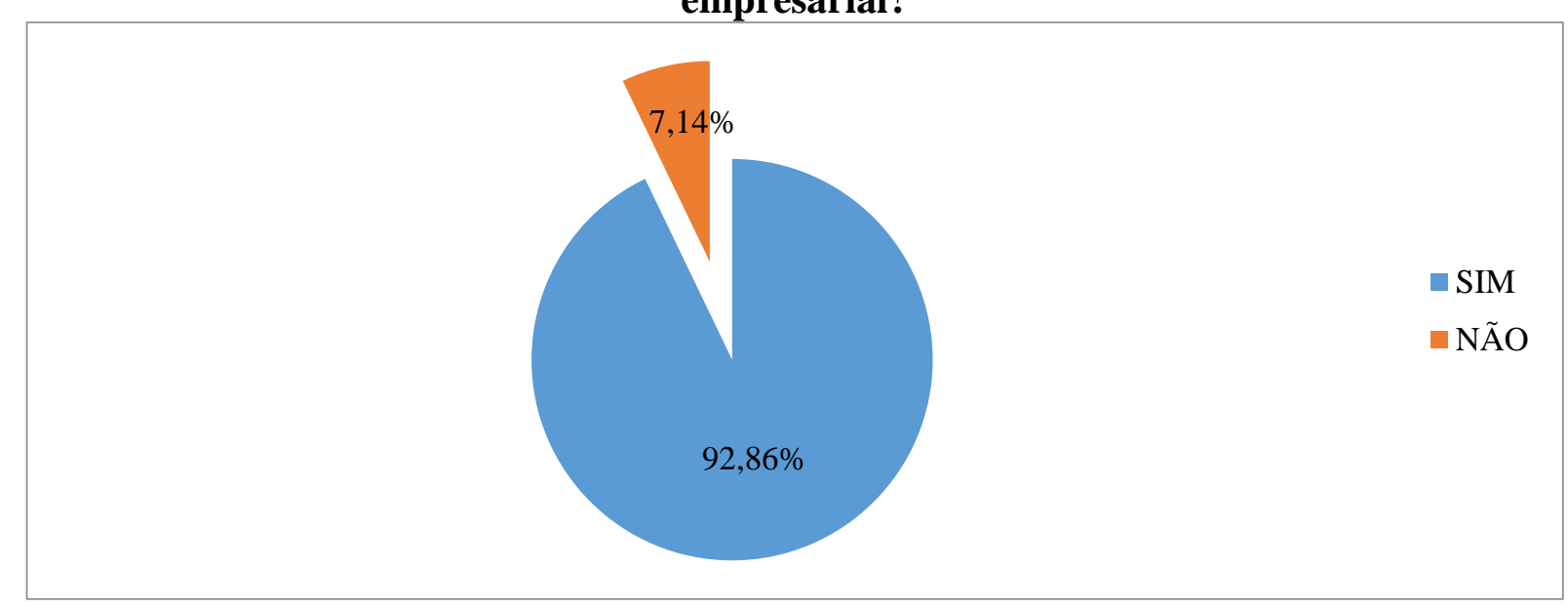

Fonte: Os autores, 2015.

O resultado do gráfico acima comprova que aperfeiçoamento sempre é positivo, pois o conhecimento irá somar em uma gestão, mostrando que $92,86 \%$ das empresas afirmaram que é necessário o aprendizado sobre gestão empresarial, um escritório é uma empresa contábil e precisa de uma gestão qualificada, 7,14\% das empresas demonstrou que não é importante esse aperfeiçoamento em gestão, ficando latente o reconhecimento por melhorias e busca por conhecimento a respeito do controle gerencial.

\section{CONSIDERAÇÕES FINAIS}

De acordo com os resultados obtidos neste trabalho de pesquisa, nas empresas prestadoras de serviços de contabilidade em geral da cidade de Caicó, existe o controle gerencial de confiança, auxiliando os gestores nas tomada de decisão. A pesquisa apresentada teve como problemática: Como os contadores veem o controle gerencial em seus respectivos escritórios na cidade de Caicó/RN? e com o objetivo geral da pesquisa: mostrar a visão dos contadores sobre o controle gerencial na cidade de Caicó/RN. Conforme os números da pesquisa feita com os empresários do ramo de contabilidade, o resultado obtido demonstrou que em sua maioria as empresas entrevistadas tem um controle gerencial de qualidade considerado ótimo ou bom, mostrando a confiabilidade no seu controle para auxiliar nas tomadas de decisões.

No presente estudo analisou alguns objetivos específicos como: 1) verificar se as empresas prestam o serviço de contabilidade gerencial para seus clientes: foi constatado que 42,86\% das 14 empresas entrevistadas prestam o serviço de contabilidade gerencial, $42,86 \%$ Volume 4, Número 8 Revista UNEMAT de Contabilidade 
prestam o serviço de informações incompleto, não auxiliando as empresas clientes com informações relevantes para tomada de decisão e 14,28\% das empresas não prestam o serviço de contabilidade gerencial; 2) saber se existe planejamento nas empresas contábeis para ter um controle: foi verificado de acordo com a análise dos resultados que 42,86\% das empresas responderam que existe planejamento, outras $42,86 \%$ responderam que existe um planejamento parcial, e que $14,28 \%$ das empresas citou que não existe planejamento, com isso chega a uma coerência que se não há planejamento também não irá existir um controle; 3) verificar na visão dos entrevistados a qualidade do controle gerencial nas empresas contábeis: constatou-se que, o controle gerencial na empresa como um todo tem uma qualidade positiva, sendo que $57,14 \%$ dos entrevistados consideraram que seu controle gerencial funciona com qualidade, podendo auxiliar nas tomadas de decisões qualificado como ótimo ou bom;4) analisar as percepções da importância do controle para os empresários: foi constatado que os empresários compreendem a importância do controle, pois 50\% dos entrevistados consideraram que todos os setores necessita de maior controle, sendo os setores pessoal, fiscal, contábil, financeiro e o setor do arquivo, onde classificado individualmente, diante das opções dos respondentes, o setor financeiro necessita de um maior controle.

O presente estudo foi de grande importância para uma melhor compreensão do controle gerencial das empresas do ramo de contabilidade, onde se observou que os empresários tem conhecimento em relação à importância do controle gerencial, a maioria coloca em pratica obtendo uma boa classificação dos controles com confiabilidade para auxiliar nas tomadas de decisões, 92,86\% dos empresários querem um aperfeiçoamento do conhecimento na área de gestão empresarial.

Recomenda-se uma pesquisa com uma maior amplitude, em outras localidades para obter um comparativo entre regiões estudadas.

\section{REFERÊNCIAS}

ANTHONY, Robert N.; GOVINDARAJAN, Vijay. Sistema de controle gerencial. 12. ed. São Paulo: Mc Graw-Hill, 2008.

Sistema de controle gerencial. São Paulo: Atlas, 2002.

BORINELLI, Márcio. Estrutura conceitual básica de Controladoria: sistematização à luz da teoria e da práxis. 2006. 341 f. Tese (Doutorado em Contabilidade) -Faculdade de Economia, Administração e Contabilidade, Universidade de São Paulo, São Paulo, 2006. 
CHIAVENATO, Idalberto. Administração: teoria, processos e praticas. 4. ed. Rio de Janeiro: Elsevier, 2007.

Introdução à teoria geral da administração: uma visão abrangente da moderna administração das organizações. 7. ed. Rio de Janeiro: Elsevier, 2003.

CREPALDI, Silvio Aparecido. Contabilidade gerencial: teoria e prática. 3. ed. São Paulo: Atlas, 2004.

FERREIRA, Deosio Cabral et al. Avaliação do Sistema de Informações Gerenciais da Assembleia Legislativa do Amazonas. Contabilidade, Gestão e Governança, v. 18, n. 2, 2015.

FIGUEIREDO, Sandra; CAGGIANO, Paulo Cesar. Controladoria: teoria e prática. 3. ed. São Paulo: Atlas, 2004.

FILHO, Milton Cordeiro Farias; FILHO, Emílio J. M. Arruda. Planejamento da pesquisa científica. São Paulo: Atlas, 2013.

FREZATTI, Fábio et al. Controle gerencial: uma abordagem da contabilidade gerencial no contexto econômico, comportamento e sociológico. São Paulo: Atlas, 2009.

FREZATTI, Fábio. Orçamento empresarial: planejamento e controle gerencial. 2. ed. São Paulo: Atlas, 2000.

GIL, Antônio Carlos. Como elaborar projetos de pesquisas. 5.ed.São Paulo: Atlas, 2010.

IUDÍCIBUS, Sergio de. Contabilidade gerencial.6.ed.São Paulo: Atlas, 2006.

MOSIMANN, Clara Pelegrinello; FISCH, Silvio. Controladoria: seu papel na administração de empresas, 2. ed. São Paulo, Atlas, 1999.

NASCIMENTO, Auster Moreira; REGINATO, Luciane (Org.). Controladoria: um enfoque na eficácia organizacional. 2. ed. São Paulo: Atlas, 2009.

PADOVEZE, Clóvis Luís. Contabilidade gerencial: um enfoque em sistema de informação contábil.4.ed. São Paulo: Atlas, 2004.

POLITELO, Leandro et al. Uma análise em organizações sob a ótica da controladoria empresarial. Desafio Online, v. 1, n. 1, p. 35-52, 2014.

SILVA, Jéssica Martins. A contabilidade como ferramenta gerencial no processo de tomada de decisão nas micro e pequenas empresas do ramo de confecções e vestuário em Goiânia. 2015.

VERGARA, Sylvia Constant. Projetos e Relatórios de Pesquisa em Administração. 14 ed. São Paulo: Atlas, 2013 